\title{
ResearchOnline@JCU
}

This is the Accepted Version of a paper published in the Journal of Rural Studies

Morrison, T.H. (2014) Developing a regional governance index: the institutional potential of rural regions. Journal of Rural Studies, 35. pp. 101111.

http://dx.doi.org/10.1016/j.jrurstud.2014.04.004

(C) 2014. This manuscript version is made available under the CC-BY-NC-ND 4.0 license http://creativecommons.org/licenses/by-nc-nd/4.0/

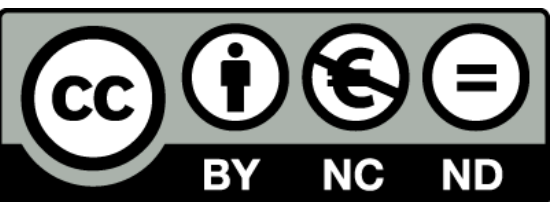




\title{
Developing a regional governance index: the institutional potential of rural regions
}

\author{
By T.H. Morrison \\ Published in Journal of Rural Studies 2014 Vol 35. Pp 101-111.
}

Please note that this publication is provided under Green Open Access. The publication is not Gold Open Access due to the publisher's copyright restrictions.

Citation: Morrison, T. H. (2014). Developing a regional governance index: The institutional potential of rural regions. Journal of Rural Studies, 35, 101-111.

\section{Developing a regional governance index: the institutional potential of rural regions}

\begin{abstract}
:
The problems of rural regions include globally uneven power relations and development patterns, and rapid and uncertain exogenous threats. At the same time, economic and social restructuring involving devolved planning responsibilities, privatised resource rights, and networked management approaches have undermined previous scholarly and policy assumptions about the character of rural regions. We already know that local and regional institutions play a critical role in ensuring the resilience and resourcefulness of rural regions in the face of such challenges. We do not yet understand why some rural regions are resourceful while others strain or even paralyse under conditions of inequity, complexity, uncertainty, and unpredictability. This paper seeks to identify the operational elements of effective regional governance, based on the premise that measuring and monitoring the potential for regional governance enables an assessment of the capacity of regional institutions to cope with the diversity of problems that may arise. A regional governance index is proposed. Four indicators of regional governance are identified, enabling measurement of (1) engagement in regional networks; (2) diversity and synergies across the instrument mix; (3) robustness and adaptability in instrument design; and (4) broader fiscal, administrative and democratic support. These indicators are tested using a case analysis of two rural regions in the USA and Australia. The test reveals the higher level of regional institutional potential in one of the regions, and highlights the critical function of regional network engagement and broader enabling fiscal, administrative and democratic preconditions in this region. The role of the state in organizing the conditions for these is shown to be vital. These findings are of use to particular regions concerned with enhancing their institutional performance, and can also assist government agencies and nonprofits to prioritise their investment and intervention in rural regions. Further development of systematic work in this domain needs to focus on the role and tools of the state, and other 'metagovernors', in organizing both the conditions for regional network engagement, and the broader enabling fiscal, administrative and democratic pre-conditions.
\end{abstract}

Keywords: rural; regional; institutions; governance; 


\section{Highlights}

- A regional governance index for assessing regional institutional potential is established.

- The index measures regional network engagement; diversity and synergy across the instrument mix; robustness and adaptability in instrument design; and broader fiscal, administrative and democratic support.

- The index is tested using a case analysis of two rural regions.

- The critical function of regional network engagement and broader enabling fiscal, administrative and democratic pre-conditions is highlighted.

- Further research needs to focus on the role and tools of the state, and other 'metagovernors', in organizing the conditions and pre-conditions for these.

\section{Introduction}

While recent international attention has focused on global processes of change, rural regions have come under increasing threat from rapid pressures. After decades of intense economic restructuring, productivist resource development, and demographic change, the problems of rural regions now not only include globally uneven power relations and development patterns, but also complex and uncertain problems such as climate change, biodiversity loss, unconventional resource development, land-use conflict, pandemic disease, and rapid market fluctuations. The spectre of a global food security crisis has even been raised (Dibden et al. 2013). These problems challenge the abilities of rural regions to respond to change in traditional ways (Hulme 2008; Woods 2012).

This is occurring at a time when the broader rural project is part of a global experimentation in statecraft, symptomatic of the post-Third-Way-period. Wider shifts in ways of governing, from central top-down control to devolved, privatised and networked modes of governance have resulted in "the new normal" of "institutional blending" and "hybridity" (Lockie and Higgins 2007; Hodge and Adams 2013). The empirical literature on governance complexity and failure to achieve outcomes is growing (Rayner and Howlett 2009; Lurie, 2011; Bakker 2012).

As a reaction to these problems, the concept of "resilience" has invariably been invoked. What constitutes resilience, and how it is measured and managed, has been debated extensively in the international literature (e.g. Skerrat 2013). Various scholars have expressed concern at the migration of an ecological concept (along with "systems" and "adaptation" concepts) to socio-political domains. Others have lamented its increasing use by government agencies as jargon for abrogating responsibility to rural communities and obscuring national and global responsibilities, citing uneven and "vanguard" driven results. Some have gone so far as to propose "resourcefulness" as a more progressive concept for understanding and managing socio-political relations at regional scales (MacKinnon and Driscoll Derickson 2013). Yet, whether "resilient" or "resourceful", at the heart of these concepts is the idea that there is something about a rural region that enables it to cope with globally uneven power and development patterns and rapid and unpredictable change.

Regional institutions - defined here as the enduring yet adaptable rules, norms and organisation of societal functioning at the regional scale - have been identified as playing a critical role in ensuring successful coping in the face of such challenges (Putnam 1993, Peters 2012). Yet some rural sociologists have documented an institutional void in rural regions as a 
result of remoteness from decision-making centres and limited local capacity (Cheshire 2010). Rural policy scholars have also documented the persistence of singular or boutique institutional responses according to the predominant land use (e.g. forestry/mining/agriculture) (Derkzen, et al. 2009). And whereas rural regions were once the crucible of innovation for socio-economic and environmental policy (e.g. the Tennessee Valley Authority), rural economists have highlighted that rural institutions and the conditions of rurality (as opposed to the benefits expropriated) are these days elided in favour of other wider policy concerns (Renwick et al. 2013; also Tietz 2012).

More recent scholarship has provided a counterpoint to the idea that rural institutions are simple, absent or excluded, and have highlighted the increasingly complex modes of governance in rural regions (Morrison, 2007, Hodge and Adams 2013). They argue that rural regions are not suffering as much from an institutional void, as that increasingly hybrid arrangements have rendered the institutional form illusive (Morrison et al. 2012, Cheshire et al. 2014). Economic and social restructuring involving devolved planning responsibilities, privatised resource rights, and networked management approaches have created this complexity, and undermined previous scholarly and policy assumptions about the institutional character of rural regions. Put simply, rural institutions are neither absent nor simple nor excluded, they are relational, thick, contextual, and complex. Furthermore, rural regions and their communities are principal locations for a range of crucial policy issues, from climate change to food and energy security to biodiversity to ecosystem services to amenity for recreation and tourism. They deserve particular attention, because not only are they on the losing end of globally uneven power relations and development patterns, but they are also at the pointy end of climate change, biodiversity loss, and land-use conflict. The institutional resilience and resourcefulness of rural regions in the face of these global relations and exogenous threats is therefore critical to both rural and urban futures.

Yet the general conception of rural institutions - as relational, thick, contextual, and complex - has rendered regional governance (and indeed rural regions) as difficult to understand and operationalize (Jonas 2012 and Rodriguez-Pose 2013). Furthermore, while there has been some important theoretical and single case study work in this domain (e.g. Ostrom 1990) there has been with very little systematic comparative work on how rural institutional relations effectively respond to increasing inequity, complexity and change. It is necessary to ask: How might a relational, thick, contextual, and complex understanding of institutions and governance shed light on the state and territorial politics in rural regions? What are the institutional factors affecting the potential of regional governance? And at what point do the state and other actors intervene?

While there are a number of strands across the social sciences which deal with different aspects of regional institutions and governance, a comprehensive analytical framework for comparatively assessing the institutional potential of governance at the regional level is yet to be developed. This paper sets out to develop and apply such a framework in order to answer these questions.

The paper begins by synthesising the different strands across the social sciences in order to provide a comprehensive understanding of rural regions, regional institutions, and regional governance. Regional governance is defined as diverse but networked policy-making and implementation arrangements over time and scale, a view which is necessary because it includes both the self-organised and centrally-steered coordination of diverse institutional actors and instruments, and therefore an integrated focus on complex sets of relationships and 
instruments over space, level and time within a region. Drawing on broad principles in political science and sociology, and applied empirics in public administration, management, and law, the operational elements of cross-sectoral, cross-instrument, inter-temporal and cross-scalar interactions in regional governance are then isolated. The importance of regional governing capacity, regional institutional diversity, regional institutional design, and regional institutional context is highlighted.

This enables the development of a regional governance index, with four primary indicators and associated metrics, relating to (1) levels of engagement in regional networks; (2) levels of diversity and synergy across the instrument mix; (3) levels of robustness and 'adaptability' in instrument design; and (4) levels of broader fiscal, administrative, and democratic support. These indicators are tested using a comparative case analysis of two rural regions, from northeastern Australia and the midwestern United States of America (USA). Taking into account administrative, fiscal, democratic and environmental differences, application of case study data to the index is shown to explain the higher level of regional institutional potential in one of the regions, which correlates with other published work on the overall resilience or resourcefulness of these two regions. The discussion then highlights the critical function of regional network engagement and broader enabling fiscal, administrative and democratic preconditions in this region, and the critical role of the state in organizing the conditions for such. The paper concludes by arguing that the institutional resourcefulness of rural regions at a time of great environmental and social change - has never been more important. Further development of systematic research in this domain needs to focus on the role and tools of the state, and other 'metagovernors', in organizing the conditions for regional network engagement as well as broader enabling fiscal, administrative and democratic pre-conditions. As rural regions become more complex and subject to the combined challenges and opportunities of climate change, resource-use pressures, privatisation and institutional hybridity, there is a critical need for more systematic and comparative research in this domain.

\section{Definitions and debates about rural regions, institutions, and governance}

Research on the properties and components of rural regions, institutions, and governance has generated significant results over the last few decades. There is no single all-encompassing regional governance theory however; rather there are a number of different research fields pursuing varied methodologies across the social sciences, which shed light on different aspects of regional governance. Drawing these strands together enables a comprehensive understanding of complex regional institutions and governance.

To begin, it is necessary to first acknowledge that the notion of a region is invoked in plural ways around the world, and even within the one nation (Agnew 2013). In the European Union, for instance, regions are officially defined by the Nomenclature des Unites Territoriales Statistiques, and can cross national borders. There are also regional authorities within countries (e.g. the German Lander, Dutch Provincie, and Australian regional NRM bodies). These regions are traditionally defined according to levels of formal governmental decision-making and geographic boundaries (e.g. based on a federated model). According to this conception, regional institutional arrangements are logically nested within larger institutional arrangements - what Ostrom (1990) refers to as 'nested hierarchies' (see also Morrison 2006). A strand of human geography, by contrast, interrogates the idea of level and the organisation of governance activities according to universally accepted hierarchies of size and complexity (MacLeod and Goodwin 1999, Bulkeley 2005). These scholars are concerned 
not with the hierarchically set and bounded unit at a particular scale, but with the more fluid relational space between the units. Using this conception of relational space allows us to see the interfaces between these units. If these interfaces are considered, regions can be conceived of as a product of relations as well as that of levels and boundaries. Focusing on scale and level thus allows us to see the complex set of institutional relationships and instruments across levels and time without also distracting our attention from "the territorial mosaic of politico-administrative units" (Harrison 2013).

In resilient or resourceful regions, these complex sets of institutional relationships and instruments across levels and time are understood of as 'dense', or 'thick' (e.g. Healey 1998, Amin 2004). Critical to this understanding is recognition of the role of informal regional institutions, such as 'community' (Putnam 1993). Indeed, contemporary institutional theory ('the new institutionalism') views institutions in a blended sense as both formal and organisational (such as that enshrined in law) and sets of informal rules/norms/values (such as community rules or those made by 'street-level bureaucrats') (Peters 2012). Regional institutions, in this sense, become the enduring yet adaptable rules, norms and organisation of societal functioning at the regional scale, and manifest not just as formal government arrangements; they can be conceptualised more broadly as formal and informal sites of social interaction, negotiation, and contestation across the public, private, and voluntary spheres. They may include manifestations such as the local planning and environment courts, a regional land-use plan, an informal water management regime, the local government, the local media, cultural norms (such as patron-client relationships between government and industry), and so forth.

This focus on informal regional institutions in rural scholarship has led in recent years to a revival of the concepts of civil society and social capital as a third alternative to governments and markets. This debate emphasizes how the state must recede (decentralise, deinstitutionalise) for civil society to be revitalised and strong regional communities to be built. However, it also renders regional institutions as deeply historical and contextual, which as Putnam notes, is 'a depressing observation for those who view institutional reform as a strategy for political change' (Putnam 1993: 183). More recently, scholars have argued more optimistically that informal regional institutions are not always self-organising, but may be steered at a distance by the state (Bell and Hindmoor 2012). This networking across the public, private and voluntary sectors has also been shown to be multiscalar (Morrison 2007).

In summary, there is general agreement in the literature that regional governance is no longer a bounded singular arrangement but characterized by diverse and networked policy-making and implementation arrangements over time and scale, diverse institutional actors and policy instruments, and both self-organized and centrally-steered choreography of actors. Regional institutions and regional governance are therefore - in essence - relational, thick, contextual, and complex. However, not only do these notions challenge traditional notions of legitimacy and efficiency in decision-making, they render regional governance inherently difficult to understand and to operationalize (Jonas 2012; Morrison et al. 2012; Rodriguez-Pose 2013). Indeed, one of the limitations of the regional governance literature in many respects is that it has yet to evidence its ability to achieve operational outcomes in a general sense, as opposed to broad principles or small examples. Given contemporary conceptualisations, it is necessary to ask: How do we understand regional institutions and governance? What factors affect the potential of regional governance? And how can the state and other actors intervene?

\section{Common themes on institutional 'potential': toward an index of regional governance}


While there is no generally agreed upon definition of regional governance, or of "good" regional governance, four desirable factors are commonly found in the theoretical and applied literature on regions.

First, it is necessary to turn to Ostrom's classic work Governing the Commons: The Evolution of Institutions for Collective Action (1990) - a critical text for understanding the role of local and regional institutions in rural regions. In this key work, the region is seen as the basic site of collective action. Regional communities are thought to be small enough in size and complexity to allow citizens informally and endogenously to make decisions about their own problems, and yet large enough to mobilise the significant voluntary capacity required to manage these problems. For the most part, this model is thought to be overwhelmingly positive. A growing body of empirical work on the positive implications of moving towards a regional governance model has emerged. Much of this work is normative in characteraimed at identifying best practice in regional governance-and focuses on collaborative strategic planning activities combined with either amalgamations of local organisations, or reconfiguration of the boundaries of administrative responsibility. Central to all of these concerns is the view that successful regions are the product of the collective, bottom-up action of intra-regional actors, nested in a polycentric fashion within government hierarchies (Andersson and Ostrom 2008). Yet it is important to caution here against one-size-fits-all regional institutional solutions (Rodrigues-Pose 2013). In targeting the institutional factors (rather then the institutions themselves) which affect regional potential the importance of central and regional networking across different levels of government, industry, and community is also emphasised (Morrison 2007). Such networking occurs through formal and informal institutional links between governmental, private, and voluntary actors with shared interests in public policy-making and implementation. Regional institutional potential is therefore dependent on the way in which informal community arrangements and more formal institutions interact to respond collectively to problems. In essence, a region is resourceful if it has this integrated governing capacity to adapt to unforeseen events.

Second, it is useful to turn to the legal, public administration and management scholarship which is explicitly concerned with how these dimensions of governance work. This body of work focuses on regional instruments of governance, including both spatial planning and regionally focused policy instruments (Howlett et al. 2006, Howlett 2009). Regional land-use planning, for instance, treats the region as a naturally occurring whole whereby territorial space is subdivided, classified, and collaboratively planned according to differences across landscapes. Other policy change can be orchestrated by legal imperatives, legislative restrictions, or indirect policy mechanisms such as economic instruments promoting regional organisation and civic action. The need to consider how this broad range of instruments interacts is essential to understanding regional institutional resourcefulness. Informal means also need to be considered. The development of legal concepts by end users in response to social mores (e.g. through the drafting of specific terms and conditions of insurance policies), for example, can drive interactive organisational behaviour and therefore regional institutional resilience. This body of scholarship shows how a thorough understanding of the interactions across laws, policies, subsidies and social mores - for example - is essential to both assessing regional resourcefulness and understanding how institutions cope in the face of rapid and complex change. The consensus is that diversified yet synergistic institutional arrangements provide a region with greater resistance against rapid and unexpected change (Howlett et al. 2006, Wilson 2010). A region is therefore also resourceful if it exhibits a welldeveloped and well-balanced mix of institutional arrangements. 
Third, these scholars also argue that policy instruments need to be designed as part of a longterm adaptive plan and approach. Gunningham and Sinclair (2005) term this 'temporal coordination'. Evidence of long-term adaptive planning can include regional plans based on scenario modelling and assessment, periodic review of policy and institutional arrangements (e.g. program evaluation, sunset clauses to legislation, indexation), and sequencing of policy instruments over time (e.g. voluntary agreements with industry to reduce water consumption which then escalate to legislated targets if industry does not deliver). This involves both 'adaptability' and robustness in institutional design, whereby robustness can be defined as resistance to change which is inappropriate or not relevant to that specific context, and 'adaptability' is concerned more with flexibility in response to relevant changes in the factual or evaluative universe (Goodin 1996). Thus, regional institutional potential also involves the ability to absorb disturbance while undergoing change in a way that essential function, structure, and identity are retained or enhanced.

Finally, the paradox of resourceful regions is that they rely upon substantial alignment of local and central political will, and central fiscal and administrative support (Tendler 1997, Crook and Manor 1998). Here, the region is not only seen as a key site of social interaction, it is also a key site of control. The principle of subsidiarity, according to which government functions should be carried out at the lowest feasible level, is also often invoked here, with its inherent bias towards the local management of particular policy issues. However, it is the role of the centre to enable regional strategies through providing the fiscal, administrative, and democratic preconditions for bottom-up adaptation (Crook and Manor 1998). It is also the role of the centre to facilitate integration and coherence through a strong leading institution, employment of personnel in units of other institutions, creation of interdepartmental units, designation of spatial planning regions, and provision of democratic space for regional actors (Jordan and Schout 2006). Governments usually delegate the responsibility to carry out specific functions to sub-national levels in response to calls for empowerment, but also retain ultimate control (deconcentration, rather than decentralisation). Regional governance potential therefore requires substantial broader support, from local citizens to central government, the bureaucracy, and larger advocacy coalitions.

\section{Measuring the different dimensions of regional governance}

It is with this lens that a regional governance index can now be developed. However, before proposing a regional governance index, it is useful to summarise previous efforts at measuring governance and measuring regions.

Scholars in many disciplines have developed different versions of governance indices. In the field of business, corporate governance indices measure different aspects of the system by which companies are directed and controlled (Klapper and Love 2004). In development economics, the quality of formal institutions is measured using indicators which track the functioning of basic qualities of the nation state such as the transparency of political processes, the quality of the bureaucracy, measures of participation and accountability, and control of corruption (Kaufmann, Kraay, and Maastruzzi 2007). In political science, decentralisation indices measure local governments according to participation, accountability, and performance (Tendler 1997, Crook and Manor 1998). In sociology, civil society indices measure democratic participation in government and society (Putnam 2000; Andersen et al. 2006; van Ingen 2008). Central to all of these scholarly developments is the idea of metrics, and of using standard index methodology to measure different aspects of governance. 
A number of resource planners and economists (e.g. Robins and Dovers 2007, Chuanpagdee and Jentoft 2009) have also attempted to develop regional governability indices. Governability, in this sense, refers to the ability to govern through enactment and enforcement. These governability indices have made significant contributions to the study of specific natural resource industries such as fisheries and/or agriculture. Much less attention has been paid, however, to regions already characterised by complex and crowded institutional arrangements, such as multifunctional rural systems (Holmes 2006). In these regions, the level of coordination, interplay, and cohesion across government groups and organisations is rarely measured (Howlett et al. 2006). This paper is concerned with the governance potential of these complex institutional systems.

Drawing on the four key factors outlined above, it therefore becomes possible to identify four primary indicators of regional governance potential, although the metrics suggested below may be applied with a view to revealing others:

(1) Levels of engagement in regional networks. High engagement by organisations and individuals in regional networks or organisations facilitates the coordination of policy goals at the same level (e.g. local, regional). This can include both cross-sectoral coordination and/or collaboration between government and community. As has been observed elsewhere (see Lane and Morrison 2006), horizontal coordination has been strongly advocated by governments and communities in recent times. In some arenas, this mode of coordination has become dominant (Lurie 2011). Knowing which local and regional organisations and individuals are involved, and how they are coordinating policy-making and implementation, is central to measuring the institutional resourcefulness of regions. This can be achieved by apprising the number of key regional networking arrangements, such as inter-organisational meetings, coordinating bodies, and co-located personnel arrangements, and then measuring the level of key actor engagement within those networks.

(2) Levels of diversity and synergy across the instrument mix. This occurs when the instruments (e.g. development assessment, taxation, incentives, voluntary agreements, spatial planning, regulation, building codes, social mores) by which policy goals are attained are also coordinated cross-sectorally. Gunningham and Sinclair (2005) warn that combinations of instruments (e.g. incentive-based instruments and liability rules) are not always synergistic, and can actually have negative effects. Seemingly contradictory responses to different aspects of complex problems can often be understood in terms of instrument interactions, which are crucial to regional resourcefulness. This can be achieved by first undertaking an inventory of the major organisations and legal/policy/program objectives influencing a region, and then screening the instruments and arrangements by which these objectives are met according to a simple matrix which shows regional objectives on the horizontal axis and sectoral objectives along the vertical axis (Howlett 2009; Nilsson et al. 2012). The levels of synergy can be scored as strong/positive (1), or weak/not known (0). In looking for evidence, analysts should look for inter-agency referrals, acknowledgment of trade-offs and co-benefit side-effects, and obvious contradictions and gaps in implementation and outputs.

(3) Levels of robustness and adaptability in instrument design. This occurs when policy instruments are designed as part of a long-term adaptive plan and approach. Gunningham and Sinclair (2005) term this 'temporal coordination'. Evidence of 
long-term adaptive planning can include regional plans based on scenario modelling and assessment, periodic review of policy and institutional arrangements (e.g. program evaluation, sunset clauses to legislation, indexation), and sequencing of policy instruments over time (e.g. voluntary agreements with industry to reduce water consumption which then escalate to legislated targets if industry does not deliver).

(4) Levels of broader fiscal, administrative and democratic support. This occurs where policy goals at different spatial scales, from local to central, are synergistic. The European multilevel governance literature has identified numerous examples of policies pursued at higher scales that clash at attempts to adapt at more local scales, and the North American literature (Rayner and Howlett 2009) shows that historical patronage relations between government and industry can ruin even the best attempts at tripartite regional governance. The development literature also emphasises how interaction between government and civil society can enhance local legibility and legitimacy. Knowing how governance is vertically coordinated across all of these scales is therefore another dimension of measuring regional institutional resilience. This can be achieved by examining the number and strength of key broader supports, such as whether there is a joint central body or coordinating legislation or policy, whether regions have been designated for implementation, whether fiscal transfers exist from central to regional for coordinated programs, whether local citizens, state, and non-state actors participate in regional and central networks (Tendler 1997), and whether these actors themselves have achieved a level of organisational fidelity or robustness.

Table 1 summarises the regional governance index according to the four primary indicators and their associated metrics.

<Insert about here: Table1: Measuring the four dimensions of regional governance>

\section{A preliminary test of the four dimensions of regional governance}

This section reports on a preliminary test of the four indicators in two regions, and the data and methods involved. The two case study regions are first introduced and the methods involved are explained. The results for each indicator in the two regions are then analysed and discussed. The section concludes by reflecting on the overall institutional resourcefulness of each region, the utility of the test and the utility of the index.

\section{1 Research design and methods}

A preliminary test of the index was undertaken in order to confirm its utility. The index was tested in two regions: North East Wisconsin, USA, and Far North Queensland, Australia. These case studies were chosen as they are similarly sized multifunctional rural regions in post-productivist federated states, regarded as models of public administration and reform, particularly as it pertains to managing the complex interplay of state and non-state actors. The two countries have for more than a century exchanged ideas and experience in federalism, regional development, and democracy.

The North East Wisconsin (NEW) region is a 30,000 square kilometre area located in the Great Lakes environment of mid-western USA (see Figure 2). The main population centers in this region include the famous Green Bay (the largest city, with a population over 100,000), 
the sprawling Fox Cities (Appleton, Osh Kosh and Fond du Lac) at the meeting of the Fox and Wolf Rivers on Lake Winnebago, and the smaller rural centers of Marinette, Manitowoc and Sheboygan (on Lake Michigan). The region has approximately 1.2 million residents, and includes two Native American Reservations. It is a resource dependent region, with the major traditional employers being in forestry and paper manufacturing, agriculture and aquaculture, tourism and recreation, and gaming. The Far North Queensland (FNQ) region is a 25000 square kilometre area located in the wet tropics of north-eastern Australia (see Figure 3). The main population centres in this region include Cairns (a coastal tourist city) and Atherton, Innisfail, Cardwell and Mossman (smaller rural towns). The region has approximately 220 000 permanent residents, including a relatively high indigenous population. Despite over 3 million domestic and international visitors each year, it is relatively remote from the key decision-making centres of Brisbane (the provincial capital) and Canberra (the national capital). FNQ is also a resource dependent region, with the traditional employers being in forestry, agriculture (dairying, sugar, pastoral), fishing and tourism.

Both regions exist within liberal democracies with significant natural resource economies and vast amounts of public land. While they have different histories of colonialism, different political systems and different natural resource endowments, they have adopted similar development ideologies and post-productivist strategies which mean that institutional arrangements are worthy of comparison in that they enable illumination of the characteristics, enabling or constraining, under which regional governance operates. Precedents for undertaking a cross-national analysis of this kind are provided by the comparative studies by Jordan and Lenschow (2008), Margerum (2008), and Benson et al. (2013) of a range of countries (including Australia and the USA) in relation to collaboration and integration of policy and management.

Analysing the regional governance of these two regions enables both a preliminary test of the index in these two regions, and an analysis of how regional governance patterns correlate with other published work on the institutional capacity of these two regions (e.g. Mazmanian and Kraft 1999; Putnam 2000; McDonald and Lane 2000; Robins and Dovers 2007; Genskow 2009; Taylor 2010).

\section{<Insert about here: Figure 1: North East Wisconsin USA>}

The index essentially measures the articulation and coordination of diverse institutional actors and instruments over space and time within each of these regions. Government agencies and non-government (industry and community) associations (and some independent citizens) are the key actors in representative democracies such as the USA and Australia. Defining this population at the regional level initially entailed scoping the range of formal regional initiatives in each region between 2000 and 2010. Choosing this time period enabled a mature analysis of institutional resilience over this period.

In order to find out which agencies, associations and individuals were involved, members of one regional initiative (the Fox Wolf Basin Advisory Council in NEW and the Far North Queensland Regional Plan Implementation Coordination Group in FNQ) were asked to nominate other members of the same population (of actors involved in regional initiatives) (snowballing). These were cross-checked against lists of actors from other regional meetings. These actors were then asked to nominate other actors. Saturation point was reached when the same actors began to be repeated. As it was not possible to collect data from all two hundred or so key actors in each region, stratification was constructed to ensure that most 
types of actors were fully represented in the sample. Thirty-two different strata were delineated, involving different combinations of government and non-government actors, concerned with environmental, social, economic or multiple issues, and acting at local, regional, state and federal levels. This technique, referred to as stratified purposeful sampling, entailed classifying each actor according to these strata, and then selecting a representative sample from each of the stratified lists. Primary data were collected through stakeholder interviews (32 in each region) and participant observation. The interview questions were semi-structured and followed the general logic of the index. Secondary data were collected through unstructured key informant interviews (15 in each region) and organisational documents. Tertiary data were collected from additional sources such as publicly documented reports. Multiple sources of evidence ensured a process of triangulation along converging lines of inquiry and ensured construct validity. The same strategy was replicated in each region. A computer-based database for managing the raw data was developed to ensure reliability. The case study results were then analysed against the four dimensions of the index. The indicators were weighted equally for the purposes of the test, with levels scored according to strong/positive (1), weak/not known (0).

<Insert about here: Figure 2. Far North Queensland, Australia >

\section{Results and Discussion}

\section{1 Indicator 1: Levels of engagement in regional networks}

Levels of engagement in regional networks can be understood as the number of interorganisational organisations or fora aimed at regionally coordinated policy-making and implementation, and level of engagement of key regional actors in those arrangements. To measure Indicator 1 it was first necessary to apprise the number of key regional networking arrangements in each region. It was found that there were approximately 10 major regional networks within each region. It was then established that regional networks typically formed around 4-5 specific issues: land use planning, natural resource management, community development, economic development, and governmental coordination. The number of different types of regional issue networks varied in each region however, with more governmental coordination networks in FNQ (most likely due to the strong history of Federal intervention in this region) and more natural resource management networks in NEW (most likely due to the influence of the community-based University of Wisconsin-Extension program). It was then necessary to apprise the number of key actors within each region. It was found that there was an average of 15 key actors in each region (across government, industry and community), with slightly more actors involved at the regional level in FNQ. This again can be explained by the higher level of federal intervention in the FNQ region, and higher levels of indigenous actor participation. Levels of engagement were scored as either strong/positive (1) or weak/not known (0) (Appendix Tables 2 and 3). The major difference found was that there was a much higher level of engagement in regional networks in FNQ, even when adjusted for federal involvement. This result accords with other published research which charts the recent wave of regionalism across all policy sectors in Australia in the new millennium, compared with the persistence of localism in the USA (Benson 2013). It indicates that the FNQ region has a higher capacity for integrated governance across formal and informal arrangements.

\subsection{Indicator 2: Levels of diversity and synergy across the instrument mix}

As discussed earlier, there is a body of legal and policy studies literature which highlights the importance of diverse yet synergistic interventions in regions. This can be understood as the sum of regional synergies across major sectoral instruments and major regional objectives. 
To measure the levels of diversity and synergy across the instrument mix it was first necessary to ascertain the major regional objectives as generally agreed upon by the key actors in each region. Data analysis revealed five generally agreed upon objectives for each region, including integrated land use planning, integrated natural resource management and community economic development (both regions), and pollution control and community education (in NEW), and indigenous land management and environmental protection and education (in FNQ). These different emphases can be explained by the history of water pollution by the paper industry, and the influence of the community-based University of Wisconsin-Extension program in NEW, and the higher numbers of indigenous peoples and the existence of two World Heritage Areas in FNQ (Mazmanian and Kraft 1999, McDonald and Lane 2000; Genskow 2009, Taylor 2010). It was then necessary to ascertain the major instruments by which these regional objectives were achieved. Across both regions, these included regional land use planning regulations, funding for community-based natural resource planning and projects, and funding for community economic development projects. In NEW, there were two additional instruments at the regional level: pollution liability legislation and an associated water quality planning and permit system, and the University of Wisconsin-Extension community education program. In FNQ, there was a slightly more diverse set of arrangements - three major additional instruments at the regional level: regulation providing for indigenous land use agreements, strategies and funds; environmental regulation for world heritage areas, coastal zones and vegetation types, and regional "state of the environment" reporting. Levels of synergy were scored as either strong/positive (1) or weak/not known (0) (Appendix Tables 4 and 5). When comparing the synergies across instruments and objectives, it was found that there was no significant difference in levels of regional synergy across the two regions although FNQ was overall a more regulated region. This result accords with other published research which explains the more anti-interventionist mode of governing in the USA. In both regions we found that there were limited synergies between most of the major regional instruments and community economic development objectives. This result also accords with other published research which charts the common use of perverse economic incentives for resource-based industries in both countries. Neither region suffered from the institutional 'void' documented in other rural regions (Cheshire 2010).

\section{3 Indicator 3: Levels of robustness and adaptability in instrument design}

Adaptability and robustness in institutional design is also integral to a region's governance potential, and can be understood as the sum of robustness and adaptability characteristics across major sectoral instruments. To test the levels of robustness and adaptability in instrument design it was then necessary to assess each of the major instruments in each region according to whether they had been designed with a 10 year plus horizon, based on scenario modelling and assessment, and/or subject to periodic review. Levels of robustness and adaptability were scored as either strong/positive (1), weak/not known (0) (Appendix Tables 6 and 7). Data analysis revealed relatively high levels of robustness and adaptability for both regions. This accorded with published research on both regions. The published research on Northeast Wisconsin revealed a region that has survived a major environmental dispute over water pollution from the paper industry, and sought to respond to increasing impacts from agricultural non-point source pollution and uncontrolled development (e.g. Kraft and Mazmanian 1999). Likewise, the published research on Far North Queensland revealed a region that has survived major environmental and social conflicts (over logging of the wet tropics rainforest and indigenous self-determination) and acted in response to increasing impacts on the terrestrial and marine environment from urbanisation, tourism, agriculture and fishing (e.g. McDonald and Lane 2000). 


\subsection{Indicator 4: Levels of broader fiscal, administrative and democratic support}

Broader support, from local citizens to central government, the bureaucracy, and larger advocacy coalitions is also integral to a region's governance potential. This can be understood not only as the sum of broader fiscal, administrative and democratic supports but also the strength of those supports. To test the levels of broader fiscal, administrative and democratic support, it was necessary to assess each region according to the following criteria: regional civic and ecological awareness; education of population; civic participation; governmental fidelity; regional championship; and availability of external mandates and support. Surprisingly, in NEW, there was only one state-level mandate (compared to five in FNQ), but a similar level of national and international mandates and support across both regions. FNQ also scored higher on "regional civic and ecological awareness" and "governmental fidelity". Levels of broader support were scored as either strong/positive (1) or weak/ not known (0) (Appendix Tables 8 and 9). Overall data analysis revealed a higher level of broader support for FNQ than for NEW. This accords with research elsewhere on the "small is beautiful" paradigm in the US which has resulted in a stewardship ethic located at the landholder level, a multiplicity of local governments, and a system of intergovernmental competition, rather than collaboration (Jacobs 1998, Kettl 2002). FNQ, by contrast, appears to have benefited from the proximity of two World Heritage Areas, and three decades of intergovernmental collaboration as a result (McDonald and Lane 2000).

\section{<Insert about here: Tables 8 and 9>}

\subsection{Summary and discussion}

When tallying up the overall scores for each region (Table 1), FNQ received a higher score for regional governance than NEW, across all indicators. This roughly coincides with other published research that shows that, despite being naturally endowed, NEW is a region which has suffered historically "from widespread poverty and some of the highest unemployment rates in the nation" (Gedicks 1993:2, also see Kraft 2006), whereas FNQ, despite also being remote, has benefited from proximity to two World Heritage Areas and associated tourism and research activity, and a strong history of cooperation and ability to access external resources (Robins and Dovers, 2007). The test revealed that first, measuring the number of key regional networks and the level of actor participation within those networks provides a useful indication of the overall level of engagement in regional networks, and therefore the integrated governing capacity of a region. Second, measuring the levels of diversity and synergy across the instrument mix in each region provides a useful indication of the overall level of institutional diversification and synergies across a region and therefore the potential resourcefulness of institutions to rapid and unexpected change. Third, measuring the levels of robustness and adaptability in instrument design for each region provides a useful indication of the ability of regional governance to absorb disturbance while undergoing change in a way that essential institutional function, structure and identity are retained or enhanced. Finally, measuring the levels of broader fiscal, administrative and democratic support for each region provides a useful indication of the alignment of regional institutions with local and central political will and fiscal and administrative support. In summary, application of the data to the index explained the higher level of regional institutional potential in one of the regions (FNQ), which correlated with other published work on the overall potential of these two regions.

Overall, the analysis confirmed the general conception that regions are 'assemblages' of multiple, multiscalar, public-private networks which are contested, relational, thick, 
contextual, and complex ( $\mathrm{Li}$ 2007, Anderson and McFarlane 2011). It also enabled generalisation on the size and sophistication of governance activity across the two regions. There were approximately10-11 major networks and 13-18 key actors in each region. There were also approximately 5 generally agreed upon regional objectives, and 5-6 major instruments for achieving these. This suggests that there is a saturation point or ceiling for governance activity in regions of this size. Furthermore, all major instruments were mostly robust and adaptable (excepting community economic development instruments in both regions), and both regions exhibited similar levels of international, national, and civic support. There was also no noteworthy difference in levels of diversity and synergy across the instrument mix or levels of robustness and adaptability in instrument design across the two regions. This suggests that both regions have reached a level of governance maturity, as would be expected in established post-productivist liberal democracies such as the USA and Australia.

However, levels of engagement in regional networks and levels of broader regional support were remarkably higher in Region 2 (FNQ), which was the region also known to be more generally resilient or resourceful. This would therefore suggest that regional network engagement and broader regional support are significant determinants of the institutional potential of a region to achieve regional resilience. Therefore in answer to this paper's original question, it becomes clear that despite conditions of relationality, thickness, contextuality, and complexity, the state can intervene in regional institutions and governance. This can be achieved through all dimensions of the index, but most vitally through targeting levels of engagement in regional networks, and levels of broader support.

These types of interventions can, in fact, be understood as the governance of governance, or metagovernance, which establishes the norms that steer the entire governing process, and is vital in areas of societal significance and periods of crisis:

[States] get involved in redesigning markets, in constitutional change and the juridical re-regulation of organizational forms and objectives, in organizing the conditions for networked self-organization, in promoting social capital and the selfregulation of the professions and other forms of expertise, and, most importantly, in the collibration [re-balancing] of different forms of governance and metagovernance (Jessop 2004:70, also see Whitehead 2007, Bell and Hindmoor 2012)

In highlighting the role of networked regional engagement and broader regional support it is important to caution here that these are not a panacea for conventional bureaucratic failings, however; they need to be understood as only two dimensions of a broader system as represented by the index. Furthermore, meeting the criteria of the four dimensions of the index is not always the ultimate ideal. Rather, a regional governance index should be able to test whether the governance of a region has the capacity to cope with the diversity of integrated problems that may arise. In this perspective, regional institutional resourcefulness is not an end state. Multiple networks and instruments exist across time and space, and regional institutional resourcefulness occurs at specific moments when these align (Reed and Bruyneel 2010). Thus the index enables a test of whether the governance of a complex regional system has the capacity to cope with the diversity of problems that may arise, based on the premise that regions only need to move up the index as problems move from simple to complex.

The results also suggest that the role and tools of the "metagovernor" in influencing the institutional resourcefulness of regions as they move up the index needs to be more fully understood. While this has attracted limited attention in the regional governance literatures, 
our results suggest that the state metagoverns, for example, through regionally-focused state regulation, establishment of horizontal and vertical coordination networks at the regional level, and cultivation of regionally aware and engaged agency offices and personnel. These results also suggest that a non-state actor (for example, a regional community or activist group) can also play the role of "metagovernor". The tools of metagovernance could therefore range from the formal strategies commissioned by the central state, to the local practical strategies exerted by regional and local actors (Sorensen 2006). These are avenues for further research.

A brief reflection on the utility of the index is also necessary here. The index makes a theoretical contribution in that it enables a test of whether the governance of a complex regional system has the capacity to cope with the diversity of problems that may arise, based on the measurement of the effective articulation and coordination of diverse institutional actors and instruments over space and time within different regions. The results also have practical application in that they can be used by governments and nonprofits working at regional to international scales to: (1) assess the capacity of regional institutions to cope with the diversity of problems that may arise, (ii) identify how particular regions can enhance their institutional performance, (iii) assist government agencies and nonprofits to prioritise investment and intervention in regions, and (iv) encourage policy transfer/diffusion from more progressive regions to less progressive regions. Further testing of the research tool is required in order to refine the method (so that it can be applied more precisely and efficiently using web-based searches, an on-line survey instrument, and/or proxy indicators), test its utility in more complex regions, and calibrate the index to be more grounded and responsive to administrative, fiscal, democratic and environmental differences.

\section{Conclusions}

Resilience and/or resourcefulness in the face of shocks as a result of climate change or rapid and unplanned development is critical. While adapting to complex problems is a challenge at all scales, the general consensus is that it is at the regional level, where rural communities will bear the brunt of the impact and context-specific decisions to preserve lives, economies, and ecosystems are made (Hulme 2008). This paper provides further evidence of the complexity of contemporary rurality, and the need for new ideas about the governance of rural regions.

Research on the governance of complex rural regions is complicated by their 'wickededness' and their paradoxical propensity for both unpredictability and path-dependence (Duit and Galaz 2008). Indeed, Putnam (1993) makes the point that successful regions have deep historical roots, and that this is 'a depressing observation for those who view institutional reform as a strategy for political change'. Because of this integrated complexity, uncertainty and path dependency, assessing and managing for institutional resourcefulness is very difficult (Howlett et al. 2006).

Yet to understand why some rural regions are resourceful, while others strain or become paralysed under conditions of complexity, uncertainty, and unpredictability, we must understand the operational elements of regional governance. A regional governance lens - as developed in this paper - allowed us to explain the potential of specific regions from an institutional perspective. Identification of four indicators enabled measurement of (1) engagement in regional networks; (2) synergies across the instrument mix; (3) robustness and adaptability in instrument design; and (4) broader fiscal, administrative, and democratic 
support. The test results suggested that despite conditions of relationality, thickness, contextuality, and complexity, the state can intervene in regional institutions and governance through all dimensions of the index, but most vitally through targeting levels of engagement in regional networks and levels of broader support for regions. This type of intervention can, in fact, be understood as metagovernance, in that it establishes the general conditions that steer the broader governance process and are vital in times of societal significance and crisis. While this sheds some further light on the regional governance project, the analysis also revealed that the role and tools of the "metagovernor" in influencing the institutional resourcefulness of regions as they move up the index needs to be more fully understood. In essence, further research needs to resolve the role of the metagovernor/s, and more fully explicate the range of strategies exerted by those metagoverning actors. As rural regions become more complex and subject to the combined effects of inequity, complexity, uncertainty and unpredictability, there remains a critical need for more applied research and research implementation in this domain.

\section{References}

Agnew, J. A. (2013). Arguing with regions. Regional Studies, 47(1), 6-17.

Amin, A. (2004). Regions unbound: towards a new politics of place. Geografiska Annaler: Series B, Human Geography, 86(1), 33-44.

Andersen, R., Curtis, J., and Grabb, E. (2006). Trends in Civic Association Activity in Four Democracies. American Sociological Review, 71(3), 376-400.

Anderson, B., \& McFarlane, C. (2011). Assemblage and geography. Area, 43(2), 124-127.

Andersson, K. and Ostrom, E. (2008). Analyzing decentralized resource regimes from a polycentric perspective. Policy Sciences 41(1): 71-93.

Bakker, K. (2010). Privatizing water. Cornell University Press, New York

Bell, S., \& Hindmoor, A. (2012). Governance without Government? The Case of the Forest Stewardship Council. Public Administration, 90(1), 144-159.

Benson, D., Jordan, A., Cook, H., and Smith, L. (2013). Collaborative environmental governance: Are watershed partnerships swimming or are they sinking? Land Use Policy, 30(1), 748-757.

Bulkeley, H. (2005). Reconfiguring environmental governance: towards a politics of scales and networks. Political Geography, 24(8), 875-902.

Cheshire, L. (2010). A corporate responsibility? The constitution of fly-in, fly-out mining companies as governance partners in remote, mine-affected localities. Journal of Rural Studies, 26(1), 12-20.

Chuenpagdee, R. and S. Jentoft (2009). Governance Assessment for Fisheries and Coastal Systems: A Reality Check. Human Ecology 37(1): 109-120. 
Crook, R.C. and Manor, J. (1998), Democracy and Decentralization in South-East Asia and West Africa: Participation, Accountability, and Performance, Cambridge University Press, Cambridge.

Derkzen, P., Bock, B. B., \& Wiskerke, J. S. C. (2009). Integrated Rural Policy in Context: A Case Study on the Meaning of 'Integration' and the Politics of 'Sectoring'. Journal of Environmental Policy and Planning, 11(2), 143-163.

Dibden, J., Gibbs, D. and C. Cocklin (2013). Framing GM crops as a food security solution, Journal of Rural Studies, 29: 59-70.

Duit, A. and V. Galaz (2008). Governance and Complexity-Emerging Issues for Governance Theory. Governance 21(3): 311-335.

Gedicks, A. (1993). The New Resource Wars: Native and Environmental Struggles Against Multinational Corporations. South End Press, Boston.

Genskow, K. (2009). Catalyzing Collaboration: Wisconsin's Agency-Initiated Basin Partnerships. Environmental Management. 43:411-424.

Goodin, R. (Ed) (1996). The Theory of Institutional Design. Cambridge University Press, Cambridge.

Gunningham, N, and Sinclair, D. (2005). Policy Instrument Choice and Diffuse Source Pollution. Journal of Environmental Law 17(1) 51-81.

Harrison, J. (2013). Configuring the new "regional world": On being caught between territory and networks. Regional Studies, 42(1) 55-74.

Healey, P. (1998). Building institutional capacity through collaborative approaches to urban planning. Environment and Planning a, 30(9), 1531-1546.

Hodge, I. D., \& Adams, W. M. (2013). The future of public forests: An institutional blending approach to forest governance in England. Journal of Rural Studies, 31, 23-35.

Holmes, J. (2006). Impulses towards a multifunctional transition in rural Australia: gaps in the research agenda. Journal of Rural Studies, 22(2), 142-160.

Howlett, M. (2009). Governance modes, policy regimes and operational plans: A multi-level nested model of policy instrument choice and policy design. Policy Sciences 42(1): 73-89.

Howlett, M., Kim, J., and Weaver, P. (2006). Assessing Instrument Mixes through Program- and Agency- Level Data: Methodological Issues in Contemporary Implementation Research. Review of Policy Research, 23(1), 129-151.

Hulme, M. (2008). Geographical work at the boundaries of climate change. Transactions of the Institute of British Geographers 33 (1), 5-11. 
Jacobs, H. (1998). The 'Wisdom', but Uncertain Future, of the Wise Use Movement. In H. M. Jacobs (Ed), Who Owns America: Social Conflict Over Property Rights. University of Wisconsin Press, Madison, pp. 29-44.

Jonas, A. E. (2012). Region and place: Regionalism in question. Progress in Human Geography, 36(2), 263-272.

Jessop, B. (2004). Multilevel governance and multilevel metagovernance. Bache, I. \& M. Flinders (eds) Multi-Level Governance, Oxford University Press, Oxford, pp. 49-74.

Jordan, A. J., \& Lenschow, A. (Eds.). (2008). Innovation in environmental policy: Integrating the environment for sustainability. Edward Elgar Publishing, Cheltenham.

Jordan, A. and Schout, A. (2006).The coordination of the European Union: exploring the capacities of networked governance. Oxford University Press, Oxford.

Kaufmann, D., Kraay, A., and Mastruzzi, M. (2007). Governance Matters VI: Aggregate and Individual Governance Indicators 1996-2006. World Bank Policy Research Working Paper No. 4280, Washington, DC.

Kettl, D. F. (2002). The transformation of governance: Globalization, devolution, and the role of government. Public Administration Review, 60(6), 488-497.

Klapper, L. F. and I. Love (2004). Corporate governance, investor protection, and performance in emerging markets. Journal of Corporate Finance 10(5): 703-728.

Kraft, M. (2006). Sustainability and Water Quality: Policy Evolution in Wisconsin's FoxWolf River Basin. Public Works Management and Policy 10, 3: 202-213.

Lane, M. and Morrison, T. (2006) Public Interest or Private Agenda? Journal of Rural Studies, 232-242.

Li, T.M. (2007). Practices of assemblage and community forest management. Economy and Society, 36(2), 263-293.

Lockie, S., \& Higgins, V. (2007). Roll-out neoliberalism and hybrid practices of regulation in Australian agri-environmental governance. Journal of Rural Studies, 23(1), 1-11.

Lurie, S. D. (2011) The CALFED Bay-Delta Program: Lessons from the Rise and Fall of a Large-Scale Ecosystem Management Network, Journal of Natural Resources Policy Research, 3:3, 251-262.

MacKinnon, D. \& Driscoll Derickson, K. (2013) From resilience to resourcefulness: A critique of resilience policy and activism, Progress in Human Geography, 37 (2): 253-270.

MacLeod, G., and Goodwin, M. (1999). Space, scale and state strategy. Progress in Human Geography, 23(4), 503-527.

Margerum R. D. (2008) A typology of collaboration efforts in environmental management, Environmental Management 41: 487-500. 
Mazmanian D.A. and Kraft M.E. (Eds), (1999) Towards Sustainable Communities: Transition and Transformations in Environmental Policy. MIT Press, Cambridge.

McDonald, G. and M. Lane, Eds. (2000). Securing the Wet Tropics? The Federation Press, Sydney.

Morrison, T. H., Wilson, C., and Bell, M. (2012). The role of private corporations in regional planning and development: Opportunities and challenges for the governance of housing and land use. Journal of Rural Studies. 28 (4): 478-489.

Morrison, T. H. (2007). Multiscalar Governance and Regional Environmental Management in Australia. Space and Polity 11 (3): 227-241.

Morrison, T.H. (2006) Pursuing rural sustainability at the regional level. Journal of Planning Literature 21(2): 143-152.

Nilsson, M., Zamparutti, T., Petersen, J. E., Nykvist, B., Rudberg, P., and McGuinn, J. (2012). Understanding Policy Coherence: Analytical Framework and Examples of SectorEnvironment Policy Interactions in the EU. Environmental Policy and Governance, 22(6), 395-423.

Ostrom, E. (1990). Governing the commons : the evolution of institutions for collective action. Cambridge University Press, Cambridge.

Peters, B. G. (2012). Institutional theory in political science. Continuum, London.

Putnam, R. D. (1993). Making Democracy Work: Civic Traditions in Modern Italy. Princeton University Press, Princeton.

Putnam, R. D. (2000). Bowling Alone: the collapse and revival of American community. Simon and Schuster, New York.

Rayner, J., and Howlett, M. (2009). Implementing integrated land management in Western Canada: policy reform and the resilience of clientelism. Journal of Natural Resources Policy Research, 1(4), 321-334.

Reed, M. G., and Bruyneel, S. (2010). Rescaling environmental governance, rethinking the state: A three-dimensional review. Progress in Human Geography, 34(5), 646-653.

Renwick, A., Jansson, T., Verburg, P. H., Revoredo-Giha, C., Britz, W., Gocht, A., \& McCracken, D. (2013). Policy reform and agricultural land abandonment in the EU. Land Use Policy, 30(1), 446-457.

Robins, L. and S. Dovers. (2007). NRM regions in Australia: the 'haves' and the 'have nots'.Geographical Research, 45(3):273-290.

Rodríguez-Pose, A. (2013). Do institutions matter for regional development?. Regional Studies, 47(7), 1034-1047. 
Schout, A., and Jordan, A. (2005). Coordinated European Governance: Self- Organizing or Centrally Steered? Public Administration, 83(1), 201-220.

Skerratt, S. (2013). Enhancing the analysis of rural community resilience: Evidence from community land ownership. Journal of Rural Studies, 31, 36-46.

Sorensen, E. (2006). Metagovernance: The Changing Role of Politicians in Processes of Democratic Governance. American Review of Public Administration 36: 98-114.

Taylor, B. M. (2010). Between argument and coercion: Social coordination in rural environmental governance. Journal of Rural Studies, 26(4), 383-393.

Tendler J (1997). Good Government in the Tropics. Johns Hopkins University Press, Baltimore.

Tietz, M.B., 2012. Regional development planning. In B. Sanyal, L.J. Vale and C.D. Rosan (eds), Planning ideas that matter. Cambridge, MA: The MIT Press, pp 127- 152.

van Ingen, E. (2008). Social Participation Revisited. Acta Sociologica, 51(2), 103-121.

Whitehead, M. (2007). The architecture of partnerships. Policy \& Politics, 35(1), 3-23.

Wilson, G. (2010). Multifunctional 'Quality' and Rural Community Resilience. Transactions of the Institute of British Geographers 35(3): 364-381.

Woods, M. (2012). Rural geography III Rural futures and the future of rural geography. Progress in Human Geography, 36(1), 125-134. 